Subjetividade, Identidade

송 


\title{
A IMPORTÂNCIA DE DEVIR MINORITÁRIO Silviano Santiago e a resistência à identidade
}

\author{
Karl Posso* \\ Universidade de Manchester
}

\begin{abstract}
RESUMO
Uma reflexão sobre a crítica da subjetividade e do pensamento identitário a partir da análise da obra literária - particularmente os contos da coletânea Histórias mal contadas (2005) - e ensaística de Silviano Santiago. Examina-se como Santiago lida contra a identidade e a representação por estas limitarem a percepção da heteróclita transformação que é o ser, e se discute como o autor mostra que o problema das minorias não é o representar de contra-identidades, mas uma questão de entrar num processo de devir onde as normas da ordem majoritária são postas numa variação contínua.
\end{abstract}

\section{PALAVRAS - CHAVE}

Silviano Santiago, crítica da identidade, devir minoritário

Para tentar dizer algo conciso, mas significativo, sobre o vasto assunto que é a ideia ou crítica do "eu" no trabalho de Silviano Santiago, focarei minha análise em alguns contos da sua coletânea Histórias mal contadas (2005). ${ }^{1}$ Começarei por comentar brevemente "Uma casa no campo", que oferece uma ilustração essencial das ideias do autor sobre a subjetividade. Aqui, uma casa de campo cuidadosamente restaurada parece ser o objetivo correlativo do amor entre o narrador e o seu falecido amante. (Que a codificação social possa ter tornado este amor inaceitável é irrelevante para a história - o texto não pretende ser um manifesto dos direitos dos homossexuais). No que pode, à primeira vista, parecer uma passagem estranha, o narrador explica como a ideia de construírem juntos esta casa rural não tinha sido o resultado de conversas racionais ou de decisões concretas:

Será que idéia tem dono? Será que, sem dono, ela pode ser presenteada? (...) Não se dá de presente uma idéia a um companheiro, como não se dá de presente uma mamadeira a um bebê chorão. A idéia flutua no ambiente poluído pela convivência diária e amamenta dias e noites de conversas frustradas, de entendimentos equivocados, de subterfúgios camuflados e de horas insones. Dois corpos nus, silenciosos e solitários ficam estirados na

\footnotetext{
*karl.posso@manchester.ac.uk

${ }^{1}$ Texto de palestra originalmente pronunciada na Fundação Casa de Rui Barbosa, Rio de Janeiro, no seminário "Crítica e valor: paisagens interculturais" (outubro de 2006).
} 
cama, desprovidos de cor e sentimentos próprios, à deriva das imagens coloridas na televisão sem som. Um dia (...) tomamos o café da manhã, dispostos a procurar uma casa no campo. ${ }^{2}$

O narrador, o seu amante, a ideia e a casa são todos objetos que surgem de - são realizações de - uma virtualidade que a erótica do amor explora. A erótica explora a virtualidade a muitos níveis: o individual, o pré-individual, o entre-individuais, o entre as partes do individual. Há uma erótica inconsciente desses corpos "desprovidos de cor e sentimentos próprios" que não depende nem das decisões dos indivíduos, nem dos projetos mútuos em que eles embarcaram. Não há simplesmente um "eu" e um "ele"; nem há uma simples fusão dos dois. Nesse caso, o acontecimento do amor - ou evento de erotismo -, que surge através e entre as superfícies dos corpos do narrador e do seu amante, cria tanto sujeitos como objetos, sendo um deles a casa. Isto não é simplesmente uma reformulação da ideia estereotipada do amor como intensidade transformadora, porque isto não é simplesmente uma interação entre sujeitos individuais, mas o que Jerry Aline Flieger descreve como uma "commingling of subjects and objects in a line of flight" ["mistura de sujeitos e objetos na mesma linha de voo"] ${ }^{3}$ O amor é tanto um produto dos sujeitos e da casa como eles o são do amor; a ideia da casa e a casa propriamente dita são produtos do processo da transformação dos sujeitos - de seu devir "na mesma linha de voo" - e não uma decisão subjetiva nem dum nem do outro. No presente diegético são as sensações - o despertar - entre o corpo do narrador e a superfície dessa casa que incita o amor a prosseguir para além da morte física do amante; mas foi o amor que em primeiro lugar produziu o narrador, o amante e a casa.

"Uma casa de campo" mostra um aspecto crucial do poder literário dos contos de Santiago, aspecto esse que se baseia no fato de eles lidarem com essências - poderes de vir a ser ou devir - e não com identidades rígidas. Os seus contos ajudam-nos a compreender como nós começamos com uma multiplicidade de diferenças - afetivas, linguísticas, genéticas, geográficas, hiperdiferenciações imperceptíveis da vida, cujas regras de formação são demasiado finas para serem apanhadas na rede da abstração binária - e de como nós eventualmente temos dois sexos e duas sexualidades, ou certo número de nacionalidades, e por aí adiante, não porque a diferença foi imposta, mas antes porque a diferença foi reduzida. A diferença é diminuída de todas as possíveis variações sexuais e genéticas para codificar os corpos no binário de feminino e masculino, e o mesmo ocorre com a simplificação das origens, combinações e interações sociais para codificar os corpos com um número limitado de categorias - raça, nacionalidade, status socioeconômico. ${ }^{4}$ Essa tendência de reduzir a diferença para fixar categorias e identidades é parodiada com grande resultado no conto "Hello, Dolly!" - aqui a lógica da redução da diferença é levada a uma conclusão tanto hiperbólica como esclarecedora. Numa carta a Walter Benjamin, o narrador lamenta o fato de toda a gente se classificar como,

${ }^{2}$ SANTIAGO. Histórias mal contadas, p. 150.

${ }^{3}$ FLEIGER. Becoming-woman: Deleuze, Schreber and molecular identification, p. 43.

${ }^{4}$ COLEBROOK. Gender, p. 221; DELEUZE; GUATTARI. A thousand plateaus: capitalism and schizophrenia, p. 260-265, 275-278; MASSUMI. A user's guide to capitalism and schizophrenia: deviations from Deleuze and Guattari, p. 92. 
e se tornar, igual, ao ponto de todos terem a mesma documentação de identificação. Resumindo, a identidade na sociedade contemporânea tornou-se numa força extenuada e o narrador sente a falta da sua aura de singularidade:

Será que outro que não eu conseguirá me representar tão bem quanto eu me represento nas minhas crises de angústia, na montanha-russa da minha depressão e nos meus piques de euforia? ${ }^{5}$

A identidade e a representação limitam a percepção da heteróclita "montanharussa" de transformação que é o ser. Além disso, a resposta à pergunta colocada em "Hello, Dolly!" já foi dada por Santiago em 1981: o seu pastiche de Graciliano Ramos no romance Em liberdade é a sua mais famosa tentativa de revelar a fabricação textual de todas as identidades. Ali, em meio à narrativa autoexpansiva da "homoidade" Santiago/Ramos, todas as identidades mergulham na autodissolução. Uma identidade tem o objetivo de ser singular; mas por necessidade, para ser "identificável", ela requer ser iterável ou imitável: a sua pureza é assombrada pela sua repetibilidade suplementar - a possibilidade da sua clonagem. É por esta razão que a independência e a liberdade do indivíduo estão sempre já restritas. Isto conduz Santiago, o perturbante copiador de Ramos - e relembremos aqui o título daquele romance: Em liberdade -, a anotar o seguinte no romance $O$ falso mentiroso: memórias (2004):

Quem copia sabe que a liberdade humana é tão limitada quanto a flor o é pela haste que a sustenta no ar. Frente às intempéries. Como a fruta o é pelo cabo. Onde se dependura e não cai. A não ser de madura. (...) Quem copia não corta cordão umbilical. Pelo contrário. Coleciona cordões umbilicais ao ar livre da imaginação. Cultiva-os do mesmo modo como o útero gera gêmeos, trigêmeos, quádruplos ou quíntuplos. O bricabraque da vida é arco-íris de diferenças no céu do companheirismo. O similar é tão igual ao original quanto é diferente dele. ${ }^{6}$

Volto logo ao tema da cópia. Pelo que diz respeito ao assunto problemático da identidade e a representação "fixa" como delimitações do "arco-íris de diferenças" da realidade - do ser -, este sofre um exame mais sério no conto "Ed e Tom", a história de dois cunhados que o narrador, um acadêmico, conhece em separado em Nova York, em circunstâncias muito diferentes, no princípio dos anos 1960. A narrativa põe a seguinte questão: "O que significava para eles aquilo que exigiam de mim - ser representante dos brasileiros. O que significa representar um grupo, uma comunidade, uma cultura ou uma nação?" Aqui, Santiago desafia diretamente a "imagem dogmática do pensamento" que define o ser como uma questão de identidades estáveis e não de diferença. Pensar ontologicamente em termos de identidades estáveis é ler soluções onde há problemas, é abordar problemas em termos de soluções. ${ }^{8}$ Assim, nesse conto, o narrador parte do princípio de que a personagem Tom mantém a sua distância dos

\footnotetext{
${ }^{5}$ SANTIAGO. Histórias mal contadas, p. 156.

${ }^{6}$ SANTIAGO. O falso mentiroso: memórias, p. 184.

${ }^{7}$ SANTIAGO. Histórias mal contadas, p. 55.

${ }^{8}$ MAY. Gilles Deleuze: an introduction, p. 73-74.
} 
vizinhos por medo de represálias motivadas por preconceitos raciais: o problema de reserva ou privacidade é erradamente interpretado como uma questão duma certa identidade racial fixa, e consequentemente, a pessoa ou singularidade que é Tom é completamente mal compreendida. Para além disso, no seu decorrer, "Ed e Tom" levanos da representação de "outros convencionais" - sejam eles vítimas ou monstros sociais - com identidades políticas, étnicas ou sexuais específicas, para o problema de diferença propriamente dita: a diferença como sendo o conceito que foge aos limites categóricos da identidade e por conseguinte da representação. A escrita de Santiago alinha-se aqui com o dilema de aceitação da realidade como a transgressão constante das categorias do pensamento representacional. Assim, ao escrever sobre pedofilia nesse conto ou em relação a Lewis Carroll ou Vladimir Nabokov em "Lolita \& outras ninfetas" (1999) enquanto que a maioria defenderia o protesto contra o abuso e a opressão como sendo da maior importância - Santiago não condena nem apoia, mas antes mostra como todas as identidades são produtos ou consequências dos problemas - das diferenças - que o ser nos apresenta:

... o homem "normal" não conseguiria distinguir a ninfeta. Só aquele que é artista ou louco, infinitamente melancólico, com uma bolha de veneno a arder-lhe nas entranhas e uma chama queimando a espinha, só este poderá ser um ninfolepto. Só ele será capaz de detectar certos sinais inefáveis e diabólicos que o narrador ameaça enumerar, para logo interromper a enumeração justificando o impedimento pelo desespero, a vergonha e lágrimas de ternura. ${ }^{9}$

Contenciosamente, portanto, Santiago prefere focar no ser como diferença (perceptiva) e na identidade - neste caso da ninfeta e do ninfoleto - como seu efeito, com vista a ultrapassar uma ontologia convencional (tendo em consideração que a diferença é a particularidade que "é" e que também "não é", ou seja, é uma indeterminação implacável); ele fá-lo para questionar a maneira como poderíamos viver, ao contrário da maneira como deveríamos viver. Ou seja, é tudo uma questão de imaginação e de potencial em vez de moralidade per se.

Confundir identidades com o ser é confundir o real com o virtual; é, como disse anteriormente - e como diria Gilles Deleuze -, questão de confundir soluções com problemas. É por esta razão que a questão de uma verdade (atual), por exemplo, não tem geralmente grande importância na escrita de Santiago e são apenas as ideias interessantes e as percepções notáveis que lhe importam. Ele demonstra isto em relação ao espirituoso e inconstante Samuel de O falso mentiroso, que oferece uma versão sardônica do drama edipiano: a sua ascendência duvidosa é usada como uma oportunidade para proliferar criativamente em eus coexistentes, cada um com os seus amores, verdades e ficções específicos. Este ser compósito é inevitavelmente carregado com múltiplos pais, que acabam por pesar tanto que ele precisa de fazer tração. A personagem Samuel/ (Silviano) reflete numa vida profissional forjada no questionar de genealogias constrangedoras e na prática afirmativa de abraçar as muitas histórias, traços e paixões contraditórios, que formam e rompem qualquer chamada "identidade". Nas mãos de

${ }^{9}$ SANTIAGO. Ora (direis) puxar conversa!: ensaios literários, p. 354. 
Samuel/ (Silviano), portanto, a ontologia não é uma maneira de nos dizer o que há (quem é), mas de nos levar numa aventura que nos traz muito para além de nós próprios.

Reclamar como tenho feito que esta "imagem dogmática do pensamento" - a identidade - é ultrapassada por Santiago ao propor uma ontologia da diferença, pode parecer ousado e, talvez, até atraente. Contudo, isto então apresenta certamente um problema se pensarmos sobre identidade como a propriedade fundamental do sujeito político que lhe outorga o acesso a direitos. Como esclarece o filósofo norte-americano Todd May em relação a Deleuze, para a imagem dogmática do pensamento, existem identidades já constituídas que são representadas por pensamento, e para a teoria política liberal, há indivíduos já constituídos, os quais hão de ser representados pelo governo. Para o pensamento dogmático, a representação transmite o mundo ao pensamento, e para a teoria política liberal, a representação transmite o indivíduo ao governo. May prossegue: para o pensamento dogmático, a verdade consiste na correspondência entre o pensamento e as identidades que esta representa, e para a teoria política liberal, a legitimidade ou a justiça consiste na correspondência entre o governo e os indivíduos que representa. $O$ pensamento dogmático e a política liberal lidam com identidades e representações estáveis. A política trata-se da "representação estável de determinados interesses individuais por meio de um governo que considera e equilibra esses interesses no domínio público". ${ }^{10}$ Todavia, um problema fundamental dos governos é como representar a pluralidade de interesses de indivíduos nas densas sociedades contemporâneas. É em relação a esta questão que regresso agora ao conto "Ed e Tom" onde o narrador cita o famoso caso dos jovens que conseguiram a dessegregação na cidade de Little Rock, no estado americano de Arkansas.

Em 1957, em Little Rock, nove jovens negros lutaram pelo direito de freqüentarem uma escola secundária. Para entrarem no instituto, os jovens tiveram que ser acompanhados por mais de um milhar de pára-quedistas armados até aos dentes e com baionetas em riste, que tinham sido enviados pelo próprio Presidente Eisenhower para os proteger das hordas de brancos segregacionistas. Isto leva o narrador de "Ed e Tom" a perguntar-se a si próprio mais outra pergunta retórica:

Será que eu entendia o motivo para os cidadãos de boa vontade de Little Rock e de toda a nação norte-americana terem designado a força policial para representá-los no momento do enfrentamento ideológico? Será que entendia que a macacada fora enviada ao estado de Arkansas para representar a Justiça, que pairava acima de qualquer especificidade étnica ou partidária? ${ }^{11}$

Santiago levanta o problema de identidade em relação à contestação política e convida-nos a examiná-lo de duas maneiras. Assumimos convencionalmente que há uma norma de direitos humanos e de cidadania que deve ser concedida a todos e que deve ser separada de preconceitos e de distorção. É por esta razão que o poder presidencial se faz sentir de uma maneira tão extravagante no incidente de Little Rock: precisa de representar a nação ou de fixar a sua identidade como sinônimo de justiça e de igualdade.

\footnotetext{
${ }^{10}$ MAY. Gilles Deleuze: an introduction, p. 120-121

${ }^{11}$ SANTIAGO. Histórias mal contadas, p. 55.
} 
Mas o narrador prefere distanciar-se de tudo isto: segregacionistas brancos, direitos dos negros, políticas demasiado zelosas, hostilidade contra os defensores da lei, imagens concretas (inflexíveis) de justiça - tudo o que ele vê no caso de Little Rock é uma arena de forças, um acontecimento político que questiona apenas o que nós compreendemos ser o político e isto porque cada força cria novas distinções e diferença. O que o exemplo de Little Rock realmente ilustra é que alargar o reconhecimento não chega: dar aos jovens negros o direito de freqüentarem uma escola de brancos não muda nada, porque tal modo de reconhecimento (ou tolerância) é já o do grupo majoritário. O que os Estados Unidos são, a sua identidade, teria de mudar: não poderia continuar ligada ao modelo do indivíduo de família nuclear, branco, educado, racional e proprietário.

"Ed e Tom" mostra que o problema das minorias não é o representar ou restaurar de contra-identidades, ou voltar a uma cultura pura ou perfeitamente igualitária há muito perdida; é uma questão de entrar num processo de devir onde as constantes e as normas da ordem majoritária dominante são postas numa variação contínua. Há de fato classes, grupos étnicos e territórios nacionais, mas estes precisam de ser vistos como estabilidades relativas, como os produtos de processos que os constroem através da formação de ligações e que ao mesmo tempo os transbordam a partir de dentro. ${ }^{12}$ Santiago indica que o processo de devir é um potencial aberto para todos, mas ninguém entra aí automaticamente pela sua posição social. As minorias também podem facilmente inculcar as suas próprias constantes e normas, algo que o narrador deste conto, um imigrante, prova claramente nas assunções e julgamentos que faz sobre a condição de imigrante e sobre "os gringos"; como resultado, as minorias também têm que construir os seus próprios meios de se tornarem outros, as suas próprias "linhas de vôo" ou variação contínua. Devir minoritário, como defendem Deleuze e Guattari, é puxar as rédeas da identidade da maioria - ou nas palavras do próprio Santiago "colecionar cordões umbilicais ao ar livre da imaginação" - para investigar novas possibilidades, novas formas de devir ou de diferença que estão ainda por realizar. Esta é a filosofia do ser, do potencial e da metamorfose que Santiago expõe magistralmente com respeito ao The Strange Case of Dr Jekyll and Mr Hyde (1886) de Robert Louis Stevenson no ensaio "A ameaça do lobisomem" (1998), onde a droga do médico "não assinala um sentido único, ela não tem um fim pré-determinado pela lógica científica; ela permite o jogo das permutações até o infinito da vida humana". ${ }^{13}$

E é em relação a Santiago como crítico literário que pretendo concluir. No ensaio "Manuel Puig: A atualidade do precursor" (2005), Santiago delineia muito claramente como a literatura também precisa de devir minoritária. Um uso majoritário de literatura fixa, regulariza e estabiliza formas e significados e portanto açambarca territorializa - variações de estilos e identidades. A literatura majoritária reforça categorias e distinções que compartimentam a existência, criando consequentemente um isolamento do pessoal e do político. Este é obviamente o caso, defende Santiago, em

\footnotetext{
${ }^{12}$ MAY. Gilles Deleuze: an introduction, p. 120-121.

${ }^{13}$ SANTIAGO. O cosmopolitismo do pobre: crítica literária e crítica cultural, p. 229.
} 
O beijo da mulher aranha (1976) de Puig, um romance onde a criatividade subtil e as técnicas cinemáticas implícitas de trabalhos anteriores como Boquinhas pintadas (1969) se tornam numa parte explícita das discussões da política e das personagens estereotipadas, dando, portanto ao leitor a receita de como escrever um texto "do tipo Puig" - o que Santiago chama de "[uma] aula didática, cujo conteúdo poderá servir ao leitor menos atento na releitura dos primeiros romances". ${ }^{14}$ Pelo contrário, uma literatura minoritária perturba as regularidades dominantes e põem-nas em variação. Boquinhas pintadas e The Buenos Aires Affair (1973) congregam - copiam - as categorias majoritárias da corrente de Hollywood e da produção cultural latino-americana para logo perturbá-las ao revelarem as suas inerentes sensibilidades do "camp" no sentido do ensaio de Susan Sontag, sem, no entanto, as apontarem diretamente com o dedo, tentando etiquetá-las ou expô-las. ${ }^{15}$ A escrita anterior de Puig provou ser uma utilização minoritária de literatura porque ligava as sensibilidades da cultura de massa, "camp", sentimental, e a paranóia e o político em redes multiplicadoras do devir: no fim dos textos não restou nenhuma identidade estável - o sexual, o cultural e o político chocam e transformam-se recíproca e subtilmente. E ao ativar linhas autênticas - embora virtuais - de variação contínua entre identidades, esta escrita minoritária, como defenderia Deleuze, engata diretamente montagens coletivas de enunciação, criando não uma voz ou identidade individual, mas a voz de um povo a vir a ser, ou seja, de um povo no processo de devir outro.

Contudo, quando Puig repetiu - copiou - as suas próprias técnicas em $O$ beijo da mulher aranha - embora já tivesse sido largamente imitado por outros - o que ele mostrou sem querer foi que para repetir - para copiar - a essência da grande literatura é preciso repetir todo o seu poder para chocar e transformar. Puig, todavia, em O beijo da mulher aranha copiou com o intento de fixar (limitar) uma identidade literária específica (aqui já não copiou para revelar potenciais inerentes de transformação): ele voltou a dar-nos mais do mesmo num estilo consolidado, quando a única coisa que ele devia ter repetido era a revelação da diferença dentro do familiar, já que nas palavras do narrador lábil de O falso mentiroso: "o similar é tão igual ao original quanto é diferente dele". Um fiel imitador da escrita de Machado de Assis nunca será o próximo Machado de Assis. Ou seja, a relação do grande escritor com a literatura é a procura e não a expressão. A escrita de Silviano Santiago desde a cópia traiçoeira de Em liberdade até as suas perversas Histórias mal contadas parece estar sempre à procura de diferentes maneiras de apalpar a diferença que é o ser: nesse processo ele mostra não haver nunca um sujeito unificado, somente montagens coletivas de enunciação e que a literatura as expressa na medida em que estas não são impostas de fora e na medida em que elas existem somente como poderes diabólicos - os do seu amado Mr Hyde - poderes do devir ou forças revolucionárias a serem construídas.

\section{A}

${ }^{14}$ SANTIAGO. Ora (direis) puxar conversa!: ensaios literários, p. 378.

${ }^{15}$ SONTAG. Notes on camp (1964), p. 103-119. Como explica Lopes em “Terceiro manifesto camp”, p. 95: "O termo [camp] é de difícil tradução para o português, ainda que muito presente na nossa cultura. Como comportamento, o camp pode ser comparado à fechação, à atitude exagerada de certos homossexuais, ou simplesmente à afetação. (...) O camp se caracteriza por uma predileção pelo artificial e pelo exagero, por um tipo de esteticismo, uma forma de ver o mundo como um fenômeno estético." 


\section{A B STRACT}

A study of the critique of subjectivity and identitarian thought in the works of Silviano Santiago. Both Santiago's fiction and critical essays are examined here, although particular attention is given to short stories from the volume Histórias mal contadas (2005). Santiago's writing is shown to manifest an aversion for notions of identity and representation because these limit our perception of the heteroclite transformation that is being. Furthermore, it is argued here that his works maintain that minorities should not seek to restore counter-identities, but rather that they should foster a universal entering into a process of becoming whereby the constants of the dominant, majoritarian order are put into continuous variation.

\section{KEYWORDS}

Silviano Santiago, critique of identity, becoming minoritarian

\section{REFERÊNCIAS}

COLEBROOK, Claire. Gender. Basingstoke: Palgrave Macmillan, 2004.

DELEUZE, Gilles; GUATTARI, Félix. A thousand plateaus: capitalism and schizophrenia. Trad. Brian Massumi. London: Athlone Press, 1996.

FLEIGER, Jerry Aline. Becoming-woman: Deleuze, Schreber and Molecular Identification. In: BUCHANAN, Ian; COLEBROOK, Claire (Ed.). Deleuze and feminist theory. Edinburgh: Edinburgh University Press, 2000. p. 38-63.

LOPES, Denilson. Terceiro manifesto camp. In: outros ensaios. Rio de Janeiro: Aeroplano, 2002. p. 89-120.

. O homem que amava rapazes $e$

MASSUMI, Brian. A user's guide to capitalism and schizophrenia: deviations from Deleuze and Guattari. Cambridge, Mass.: MIT Press, 1993.

MAY, Todd. Gilles Deleuze: an introduction. Cambridge: Cambridge University Press, 2005. SANTIAGO, Silviano Em liberdade: ficção. Rio de Janeiro: Paz e Terra, 1981.

SANTIAGO, Silviano. A ameaça do lobisomem (1998). In: O cosmopolitismo do pobre: crítica literária e crítica cultural. Belo Horizonte: Editora UFMG, 2004a. p. 213-231. SANTIAGO, Silviano O falso mentiroso: memórias. Rio de Janeiro: Rocco, 2004b. SANTIAGO, Silviano. Histórias mal contadas. Rio de Janeiro: Rocco, 2005. SANTIAGO, Silviano Lolita \& outras ninfetas (1999). In: . Ora (direis) puxar conversa!: ensaios literários. Belo Horizonte: Editora UFMG, 2006a. p. 343-354.

SANTIAGO, Silviano. Manuel Puig: a atualidade do precursor (2005). In: . Ora (direis) puxar conversa!: ensaios literários. Belo Horizonte: Editora UFMG, 2006b. p. 367-381. SONTAG, Susan. Notes on camp (1964). In: . A Susan Sontag reader. Introdução de Elizabeth Hardwick. Harmondsworth: Penguin Books, 1983. p. 103-119. 